\title{
OPEN Roles of drinking and diet in the U-shaped relationship between smoking and BMI in middle-aged and elderly Chinese rural adults
}

\author{
Da Pan ${ }^{1,5}$, Shaokang Wang ${ }^{1,5}$, Ming Su ${ }^{2}$, Jie Wei ${ }^{1}$, Kai Wang ${ }^{2}$, Pengfei Luo ${ }^{3}$, James D. Smith ${ }^{4}$, \\ Gege Ma ${ }^{1}$ \& Guiju Sun ${ }^{1 \bowtie}$
}

The study aimed to investigate the relationship between smoking and BMI, from the perspective of the roles of alcohol drinking and dietary factors in a rural population. We analysed cross-sectional data from 10,837 middle-aged and elderly Chinese rural adults who completed a questionnaire that included questions on demographic characteristics, dietary intake, and detailed smoking and drinking status. Results showed that current smokers had lower BMI and consumed foods less frequently (except coriander, onion, garlic, hawthorn and fermented bean curd) than non-smokers. The relationship between smoking amount and the risk of overweight or obesity was $U$-shaped, and the trends were also similar by stratum of baseline age groups (all $p$ for interaction $<0.001$ ). Heavy smokers tended to have drinking habits, which was associated with increased BMI (all $p$ for trend < 0.001). Additionally, despite the lower risk of overweight or obesity for current smokers, normal weight individuals were found to have the minimum smoking amount. In conclusion, smoking may cause suppression of appetite but smokers tend to have other unhealthy habits relating to increased BMI. Dietary factors and alcohol use play important roles in the U-shaped relationship between smoking behaviours and BMI in the middle-aged and elderly Chinese rural population.

From the long-stemmed pipe, snuff, water pipe to the hand-rolled cigarettes and finally the manufactured cigarettes, the history of tobacco use in China started from sixteenth century, since the introduction of tobacco into China from the New World ${ }^{1}$. The history of tobacco may be a fascinating story of a commodity that became a symbol of modern mass consumerism, but the health and economic burden of smoking-related ill health should not be overlooked. Smoking is one of the most important causes of avoidable death and illness in China. With a population of nearly 1.4 billion, China is currently the largest tobacco producer and consumer worldwide, bearing a high morbidity and mortality attributable to tobacco smoking ${ }^{2}$. Interestingly, many old epidemiological studies have indicated that tobacco smoking is inversely associated with body weight, while smoking cessation is likely to result in weight gain ${ }^{3-7}$.

In fact, papers reporting that smoking reduced body weight started to appear more than a hundred years $\mathrm{ago}^{5}$, but relative studies began very late and detailed researches aiming at analysing the relationship between tobacco use and body weight in general population have rarely been studied in the last few decades. Previous studies mainly investigated the association between tobacco use and Body Mass Index (BMI) in adolescents and young adults, because some of them may smoke for intentional weight loss, especially young girls ${ }^{8-10}$. It has been reported that female adolescents may start smoking and continuing with this habit for purposes of weight control and weight loss ${ }^{11}$. These studies, however, have focused on a particular demographic (young people) and there is, in our view, a significant gap as a result. Of note, cigarette smoking may result in acute suppression of appetite via

\footnotetext{
${ }^{1}$ Key Laboratory of Environmental Medicine and Engineering of Ministry of Education, and Department of Nutrition and Food Hygiene, School of Public Health, Southeast University, Nanjing 210009, People's Republic of China. ${ }^{2}$ Huai'an District Center for Disease Control and Prevention, Huai'an, People's Republic of China. ${ }^{3}$ Jiangsu Provincial Center for Disease Control and Prevention, Nanjing 210009, People's Republic of China. 'University of Leeds, Leeds LS2 9JT, UK. ${ }^{5}$ These authors contributed equally: Da Pan and Shaokang Wang. ${ }^{\square}$ email: gjsun@ seu.edu.cn
} 


\begin{tabular}{|c|c|c|c|c|c|c|c|}
\hline \multirow[b]{2}{*}{ Body size parameter } & \multirow[b]{2}{*}{ Total $(n=10,837)$} & \multicolumn{3}{|l|}{ Current smoker } & \multicolumn{3}{|l|}{ Non-smoker } \\
\hline & & Total $(n=3007)$ & $\begin{array}{l}\text { Female } \\
(\mathrm{n}=948)\end{array}$ & Male $(n=2059)$ & $\begin{array}{l}\text { Total } \\
(\mathrm{n}=7830)\end{array}$ & $\begin{array}{l}\text { Female } \\
(n=5766)\end{array}$ & Male $(n=2064)$ \\
\hline Body Mass Index & $24.10(3.21)$ & $23.83(3.10)$ & $24.04(3.42)$ & $23.74(2.94)$ & $24.21(3.24)$ & $24.19(3.32)$ & $24.27(3.00)^{\mathrm{b}}$ \\
\hline Height $(\mathrm{cm})$ & $161.34(7.54)$ & $163.57(7.54)$ & $157.12(6.55)$ & $166.53(5.95)$ & $160.48(7.36)$ & $158.27(6.38)^{\mathrm{a}}$ & $166.69(6.32)$ \\
\hline \multirow[t]{4}{*}{ Weight (kg) } & $62.76(9.17)$ & $63.82(9.50)$ & $59.35(9.25)$ & $65.87(8.89)$ & $62.34(9.01)$ & $60.5(8.25)^{\mathrm{a}}$ & $67.53(9.05)^{\mathrm{b}}$ \\
\hline & & \multicolumn{6}{|c|}{ Body Mass Index } \\
\hline & & \multicolumn{3}{|c|}{ Male $(n=4123)$} & \multicolumn{3}{|c|}{ Female $(n=6714)$} \\
\hline & & \begin{tabular}{|l|} 
No \\
\end{tabular} & Unadjusted & Adjusted $^{c}$ & No & Unadjusted & Adjusted $^{c}$ \\
\hline \multicolumn{8}{|c|}{ Number of cigarettes smoked per day } \\
\hline Non-smoker & & 2064 & $24.27(3.00)$ & 24.32 & 5766 & $24.19(3.32)$ & 24.04 \\
\hline$<10$ & & 320 & $23.50(2.94)$ & 23.63 & 281 & $24.32(3.56)$ & 23.93 \\
\hline $10-$ & & 722 & $23.27(2.81)$ & 23.47 & 301 & $23.66(3.06)$ & 23.51 \\
\hline $20-$ & & 1017 & $24.14(2.98)$ & 23.86 & 366 & $24.12(3.56)$ & 23.69 \\
\hline \multicolumn{8}{|c|}{ Cumulative amount of smoking (pack-years) } \\
\hline Non-smoker & & 2064 & $24.27(3.00)$ & 24.32 & 5766 & $24.19(3.32)$ & 24.04 \\
\hline$<15$ & & 812 & $23.16(2.79)$ & 23.42 & 463 & $24.16(3.43)$ & 23.80 \\
\hline $15-$ & & 518 & $24.07(2.99)$ & 23.83 & 259 & $23.75(3.14)$ & 23.45 \\
\hline $30-$ & & 729 & $24.14(2.97)$ & 23.89 & 226 & $24.12(3.68)$ & 23.76 \\
\hline
\end{tabular}

Table 1. Sample characteristics of body size parameters by smoking and sex categories in study subjects (data are mean (standard deviation)). ${ }^{\mathrm{a} C o m p a r e d ~ w i t h ~ f e m a l e ~ s m o k e r s, ~} \mathrm{p}<0.05$ (Student's $\mathrm{t}$ test). ${ }^{\mathrm{b}}$ Compared with male smokers, $\mathrm{p}<0.05$ (Student's t test). 'All variables adjusted for gender, age, education level, annual income, alcohol units consumed per day and consumptions of total vegetables, fresh fruits and meats in analysis of covariance.

actions of nicotine $\mathrm{e}^{12}$. People are probably aware of its appetite-suppressing actions ${ }^{5}$, but the conclusion is inconsistent in some other studies ${ }^{13,14}$. To our knowledge, no study has yet examined these specific relationships in a middle-aged and elderly Chinese rural population in detail. In China, rural residents living in villages typically have very simple lifestyle and relatively stable dietary pattern, owing to the non-pluralistic societal environment and being generally low socio-economic class without much variation. Therefore, this study may be a good addition to the previous studies as it sampled a relatively unstudied sample group, which provides additional data.

Additionally, it was reported that smoking status had positive associations with alcohol drinking status, suggesting that heavy smokers are likely to have heavy use of alcohol ${ }^{15,16}$. Alcohol has a caloric value of $7.1 \mathrm{kcal}$ $(29 \mathrm{~kJ})$ per gram and therefore becomes a nontrivial energy source, and alcohol intake is also positively associated with intake of red meat, poultry and high-fat diet, which are possibly associated with weight gain and the development of obesity ${ }^{16,17}$. Many cross-sectional studies and some prospective cohort studies have indicated that alcohol consumption is positively associated with weight gain and thus a risk factor for obesity ${ }^{18-22}$, but some other epidemiological studies reported inconsistent results of null and inverse associations ${ }^{16,23-25}$.

Therefore, clear cause-and-effect relationships among tobacco use, alcohol consumption and BMI are not apparent so far based on the mixed and conflicting nature of available evidence. Meanwhile, detailed study on these topics is required and needs to be updated as most of the previous studies were conducted several decades ago. Given that excessive use of tobacco and alcohol and the burden of obesity are of public health concern, the aim of this study was to provide a detailed update on the association between tobacco smoking and BMI in the relatively unstudied sample of the middle-aged and elderly Chinese rural population, while considering the role of alcohol drinking status and dietary factors.

\section{Results}

Characteristics and distribution of BMI and smoking behavior variables of the subjects. Supplementary Figure S1 shows the participants flowchart of the study. Supplementary Table S1 shows the characteristics of the non-smokers and current smokers. The mean age of current smokers was significantly higher than that of non-smokers $(p<0.001)$. About $68.5 \%$ of current smokers were male, whereas $73.6 \%$ of non-smokers were female. Tables 1 and 2 describe the distribution of BMI and smoking behavior variables of the study subjects. As shown in Table 1, current smokers weigh, on average, less than non-smokers and are likely to have a lower BMI, but adjusted data of BMI suggest that heavy smokers may have a higher BMI than light smokers. The mean data shown in Table 2 reports that underweight subjects started smoking at the youngest age, and had the highest number of cigarettes smoked per day, the longest duration of smoking and largest cumulative amount of smoking among the four BMI categories. However, it is interesting to find that subjects with normal weight had the lowest mean levels of smoking status mentioned above.

Relationship between smoking behavior and BMI. As shown in Fig. 1, the analysis assessed the ORs for being overweight or obese in a multiple logistic regression model in which combinations of age groups and 


\begin{tabular}{|c|c|c|c|c|c|c|c|}
\hline \multirow[b]{2}{*}{$\begin{array}{l}\text { Smoking behavior } \\
\text { parameters }\end{array}$} & \multirow[b]{2}{*}{ Total $(n=3007)$} & \multicolumn{4}{|l|}{ BMI category } & \multicolumn{2}{|l|}{ Gender } \\
\hline & & $\begin{array}{l}\text { Underweight }(<18.5 \text {, } \\
\mathrm{n}=59)\end{array}$ & \begin{tabular}{|l|} 
Normal (18.5-23.9, \\
$n=1634)$
\end{tabular} & $\begin{array}{l}\text { Overweight (24.0- } \\
27.9, n=1023)\end{array}$ & $\begin{array}{l}\text { Obese }(\geq 28.0, \\
\mathbf{n}=291)\end{array}$ & Female $(n=948)$ & Male $(n=2059)$ \\
\hline $\begin{array}{l}\text { Age started smoking } \\
\text { (years) }\end{array}$ & $33.37(11.78)$ & $30.84(9.93)$ & $34.97(12.07)^{\mathrm{a}}$ & $31.41(11.00)^{\mathrm{b}}$ & $31.72(11.81)^{\mathrm{b}}$ & $35.20(11.26)$ & $32.52(11.92)$ \\
\hline $\begin{array}{l}\text { Number of cigarettes } \\
\text { smoked per day }\end{array}$ & $15.77(9.31)$ & $17.32(8.52)$ & $15.00(8.93)$ & $16.90(9.84)^{b}$ & $15.89(9.27)$ & $13.82(8.42)$ & $16.67(9.56)$ \\
\hline $\begin{array}{l}\text { Duration of smoking } \\
\text { (years) }\end{array}$ & $24.35(12.26)$ & $28.95(11.77)$ & $23.00(12.46)^{\mathrm{a}}$ & $25.88(11.93)^{\mathrm{b}}$ & $25.68(11.47)^{\mathrm{b}}$ & $23.58(11.74)$ & $24.71(12.48)$ \\
\hline $\begin{array}{l}\text { Cumulative amount of } \\
\text { smoking (pack-years) }\end{array}$ & $21.43(18.71)$ & $26.67(17.68)$ & $19.64(18.28)^{\mathrm{a}}$ & $23.81(19.33)^{\mathrm{b}}$ & $22.09(17.98)^{\mathrm{b}}$ & $17.95(16.06)$ & $23.03(19.60)$ \\
\hline
\end{tabular}

Table 2. Sample characteristics of smoking parameters by BMI and sex categories in study subjects. (data are mean (standard deviation)). ${ }^{\mathrm{a} C}$ Compared with underweight group, $\mathrm{p}<0.05$ (Tamhane's T2 post-hoc test). ${ }^{\mathrm{b} C o m p a r e d}$ with normal group, $\mathrm{p}<0.05$ (Tamhane's T2 post-hoc test).

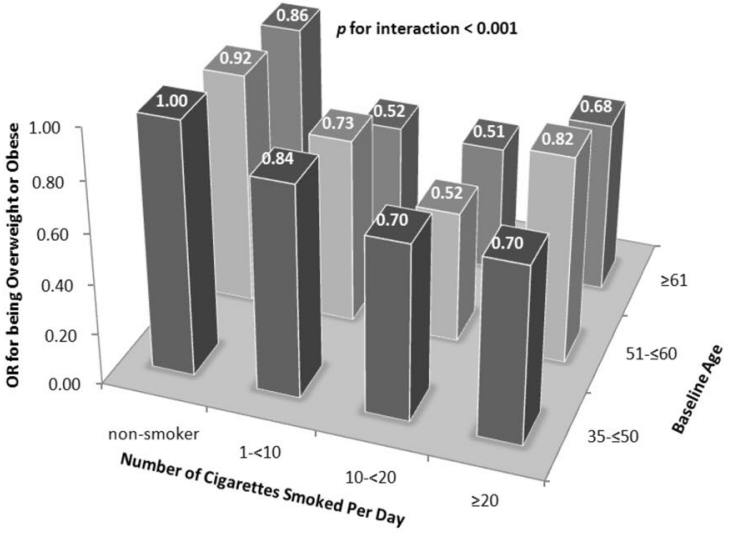

(a)

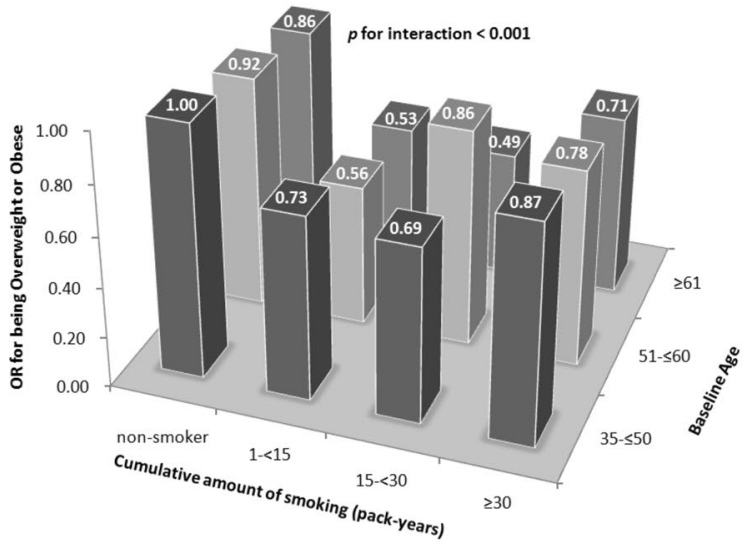

(b)

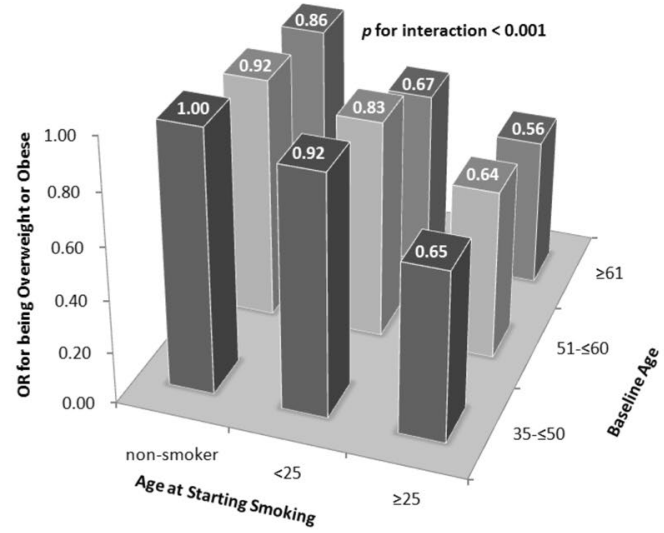

(c)

Figure 1. Odds ratios of becoming overweight or obese according to (a) number of cigarettes smoked per day, (b) cumulative amount of smoking, and (c) age at starting smoking, with model adjusted for gender, age, education level, annual income, alcohol units consumed per day, and consumptions of total vegetables, fresh fruits and meats. The figure was created using Microsoft Office Excel 2007 software.

smoking behavior parameters were used to reclassify the subjects into 9 or 12 subgroups. Compared with nonsmokers aged $35-\leq 50$ years (reference), smokers aged $\geq 61$ years who smoked $10-<20$ cigarettes $(\mathrm{OR}=0.51 ; 95 \%$ CI, 0.41-0.63), or had 15-<30 pack-years of cumulative amount of smoking (OR $=0.49 ; 95 \% \mathrm{CI}, 0.38-0.64)$, or started smoking at $\geq 25$ years old $(\mathrm{OR}=0.56 ; 95 \% \mathrm{CI}, 0.48-0.66)$ show the lowest ORs for being overweight or obese. In addition, Fig. 1 also suggests that the OR for being overweight or obese had a decreasing trend along with the increases of the baseline age group and/or age at started smoking. However, it can be found that 


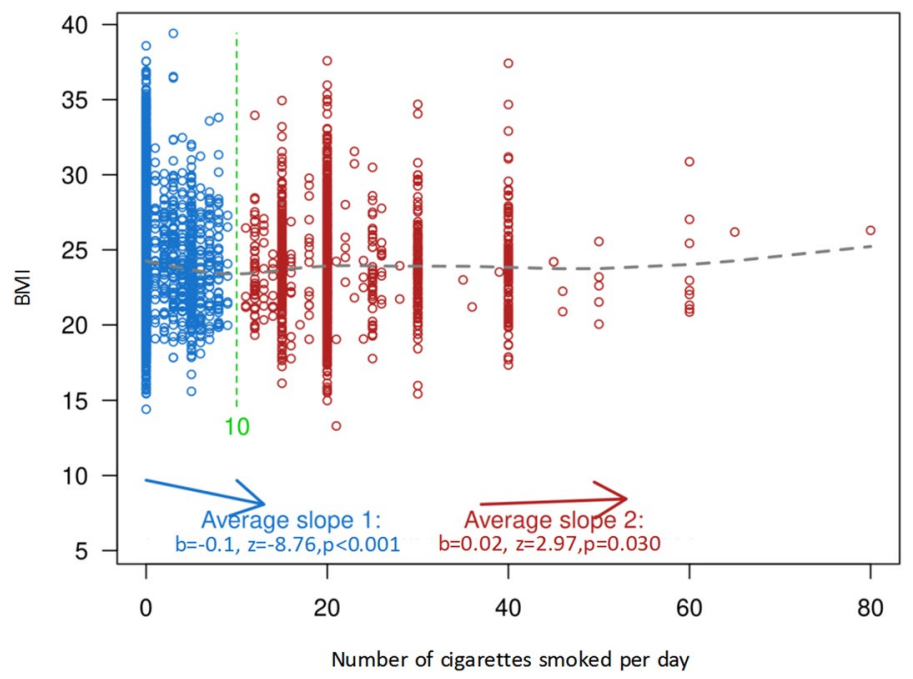

Figure 2. Two-lines test for the U-shaped relationship between number of cigarettes smoked per day and BMI, controlling for gender, age, education level, annual income, alcohol units consumed per day, and consumptions of total vegetables, fresh fruits, and meats. The chart was generated by Two-lines test version 0.52 (https://webst imate.org/twolines/).

there could be a U-shaped relationship between the number of cigarettes smoked per day/cumulative amount of smoking and the OR for being overweight or obese, with $10-<20$ cigarettes smoked per day and $15-<30$ packyears being the lowest ORs (except the one which aged $51-\leq 60$ and had $15-<30$ pack-years). The trends in risk of being overweight or obese with the changes of smoking behavior parameters were also similar by stratum of baseline age groups (all $p$ for interaction $<0.001$ ).

As shown in Fig. 2, a two-lines test was used to ascertain if the number of cigarettes smoked per day has a $\mathrm{U}$-shaped effect on BMI, controlling for gender, age, education level, annual income, alcohol units consumed per day, and consumptions of total vegetables, fresh fruits, and meats. In the test, the Robin Hood algorithm was used to set the breakpoint ${ }^{26}$, which was 10 cigarettes smoked per day. Robin Hood algorithm is developed by Uri Simonsohn to set a breakpoint that will increase the statistical strength of the weaker of the two lines in the test, by placing more observations in that segment, without overly attenuating its slope ${ }^{26}$. Between 0 and 10 cigarettes smoked per day, the relationship is significantly negatively sloped, $\mathrm{z}=-8.76, p<0.001$. Between 10 and 80 cigarettes smoked per day, the relationship is significantly positively sloped, $z=2.97, p=0.030$. Therefore, the two-lines test confirms the U-shaped relationship between smoking and BMI.

On the other hand, Fig. 3 illustrates the analysis assessing the ORs for being smokers according to the four BMI categories in a multiple logistic regression model. The OR for being smokers showed a decreasing trend along with the increase of the BMI in total subjects ( $p$ for trend $<0.001)$, as well as in the subgroups of male $(p$ for trend $<0.001$ ) and female ( $p$ for trend $=0.005$ ). Statistically, Fig. $3 \mathrm{~b}$ suggests that the data of female were more significant than those of male, and the trend was more remarkable.

Differences in dietary intake frequency between current smokers and non-smokers. Figure 4 illustrates the differences in dietary intake frequency between current smokers and non-smokers, with model adjusted for gender, age, BMI, education level, annual income and alcohol units consumed per day. It can be seen that non-smokers tended to consume most foods more frequently than smokers, whereas smokers may be more likely to consume coriander, onion, garlic, hawthorn and fermented bean curd frequently.

Adjusted data in Table 3 indicates strong positive associations between alcohol drinking behavior parameters and risk of being overweight or obese, as the statistically significant increasing trend can be found in alcohol units consumed per day, duration of drinking, earlier age at starting drinking, as well as cumulative amount of drinking (all $p$ for trend $<0.001$ ). In addition, consumptions of liquor and beer were significantly associated with $70 \%(p<0.001)$ and $48 \%(p=0.002)$ increased risks of being overweight or obese, respectively, whereas no statistical significance was found in wine consumption $(p=0.231)$.

Association between smoking behavior and risk of becoming a drinker. As can be seen from Table 4, adjusted results show strong positive associations between smoking behavior parameters and risk of becoming a drinker. The statistically significant increasing trend can be found in number of cigarettes smoked per day, duration of smoking, earlier age at starting smoking, as well as cumulative amount of smoking (all $p$ for trend $<0.001)$. Figure 5 shows the indirect effect of smoking behavior on BMI through alcohol consumption. The number of cigarettes smoked per day was significantly positively related to the alcohol units consumed per day, and the alcohol units consumed per day was significantly positively related to BMI, whereas the number of cigarettes smoked per day was negatively associated with BMI, suggesting that a suppression effect would be present within the mediation model $\left(a b>0, c^{\prime}<0\right)$. 


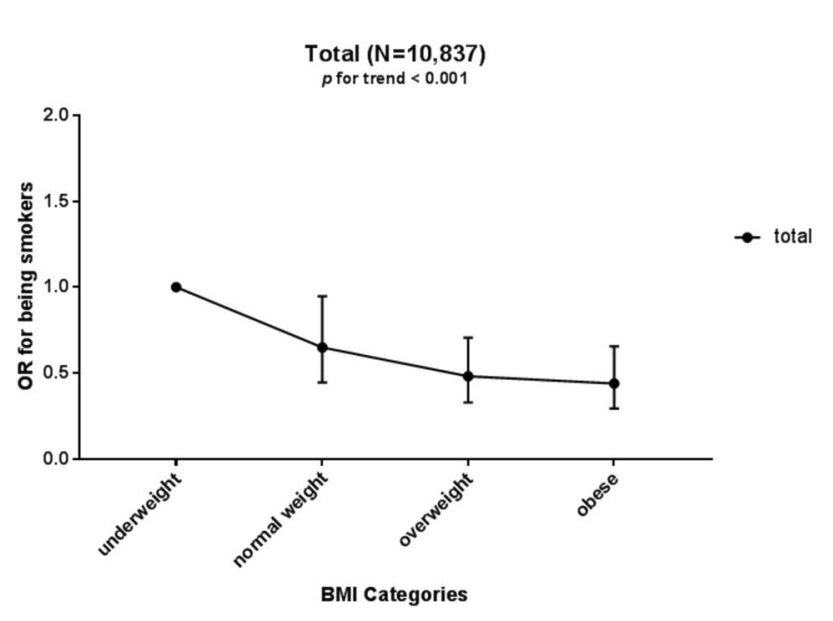

(a)

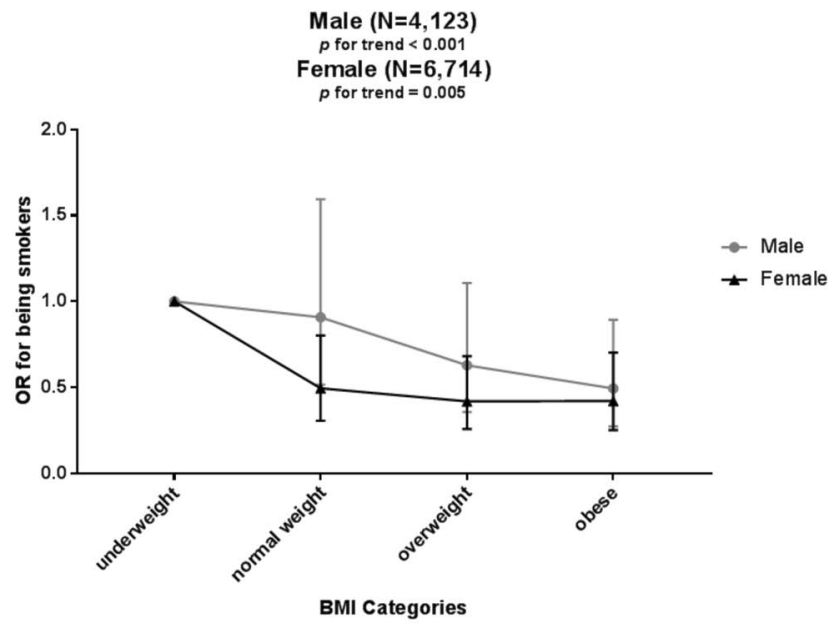

(b)

Figure 3. Odds ratios (and 95\% CIs) of being current smokers according to BMI categories in (a) total subjects, and (b) males or females, with model adjusted for gender, age, education level, annual income, alcohol units consumed per day, and consumptions of total vegetables, fresh fruits and meats. The figure was created using GraphPad Prism 7.04 (https://www.graphpad.com/).

\section{Discussion}

Based on comprehensive data from 10,837 middle-aged and elderly Chinese rural individuals, this cross-sectional study provided evidence that current smokers tended to have a lower BMI than non-smokers and thus were less likely to be overweight or obese, but the relationship might be U-shaped between amount of smoking and risk of being overweight or obese. Interestingly, individuals with normal weight would have the lowest levels of smoking behaviors among the four BMI categories, including the oldest age at starting smoking, the lowest number of cigarettes smoked per day, the shortest duration of smoking and the minimum cumulative amount of smoking. Additionally, this study also found that smokers, especially heavy smokers, were more likely to be drinkers and eat less when compared with non-smokers, whereas alcohol drinking behaviors were positively associated with the risk of being overweight or obese. These results highlighted the roles of alcohol drinking behavior and dietary factors in influencing the relationship between smoking status and BMI, which could have implications for public health interventions aiming at reducing the burdens from weight issues and harmful use of alcohol and tobacco.

A previous epidemiological study also found that young American adults aged less than 30 years who were trying to lose weight were more likely to smoke ${ }^{27}$. However, the mechanism that smoking is associated with reduced body weight is still complex and remains incompletely understood. Basically, cigarette smoking is often thought to have appetite-suppressing actions and therefore control weight ${ }^{10,12}$. As shown in Fig. 4, it is obvious that smokers tended to eat less than non-smokers, including most foods of vegetables, fruits, nuts, cereals, bean food, animal product, fried food, pickled food and food made with yeast. However, they may consume more coriander, onion, garlic, hawthorn and fermented bean curd, which are generally considered as the flavorants or foods with a strong flavor having positive effects on appetite or digestion ${ }^{28-30}$. Therefore, it can be suggested that cigarette smoking may negatively influence subjects' appetite, and result in lower consumption of food and reduced energy intake. At the individual level, when the energy intake is below the energy expenditure, a negative energy balance and consequent reduced body weight will occur ${ }^{31}$. Previous study held that on the one hand, cigarette smoking might serve as a behavioral alternative to eating, and on the other hand, nicotine in cigarettes may increase the resting metabolic rate while controlling the expected growth in food consumption in response to the growth in metabolic rate, which would tip the balance of caloric intake and daily energy expenditure, and the energy deficit in these smokers would predict a weight loss ${ }^{10}$. Interestingly, the results shown in Table 2 first reports that subjects with normal weight would have the lowest levels of smoking behaviors among the four BMI categories, which suggests that normal weight individuals may be more likely to have a relatively healthier lifestyle. In other words, subjects rarely or never smoked may be typically more likely to be within a normal BMI range than regular or heavy smokers, because they were less influenced by weight loss or weight gain caused by smoking or smoking cessation.

Among subjects a U-shaped relationship between the number of cigarettes smoked per day/cumulative amount of smoking and the OR for being overweight or obese can be found in Figs. 1 and 2, with $10-<20$ cigarettes smoked per day and $15-<30$ pack-years being the lowest ORs (except the one which aged $51-\leq 60$ and had $15-<30$ pack-years), as well as the breakpoint of 10 cigarettes smoked per day found by the two-lines test. This finding is exactly consistent with several early studies, which have concluded that individuals smoked about 10-20 cigarettes per day were the leanest, with the trend being similar by stratum of baseline age groups $\mathrm{s}^{3,4,32-39}$. Therefore, studies have reported that there is not just simply negative relationship between smoking amount and $\mathrm{BMI}$ or body weight, whereas the observed U-shaped relationship is by no means coincidental. Although this may 


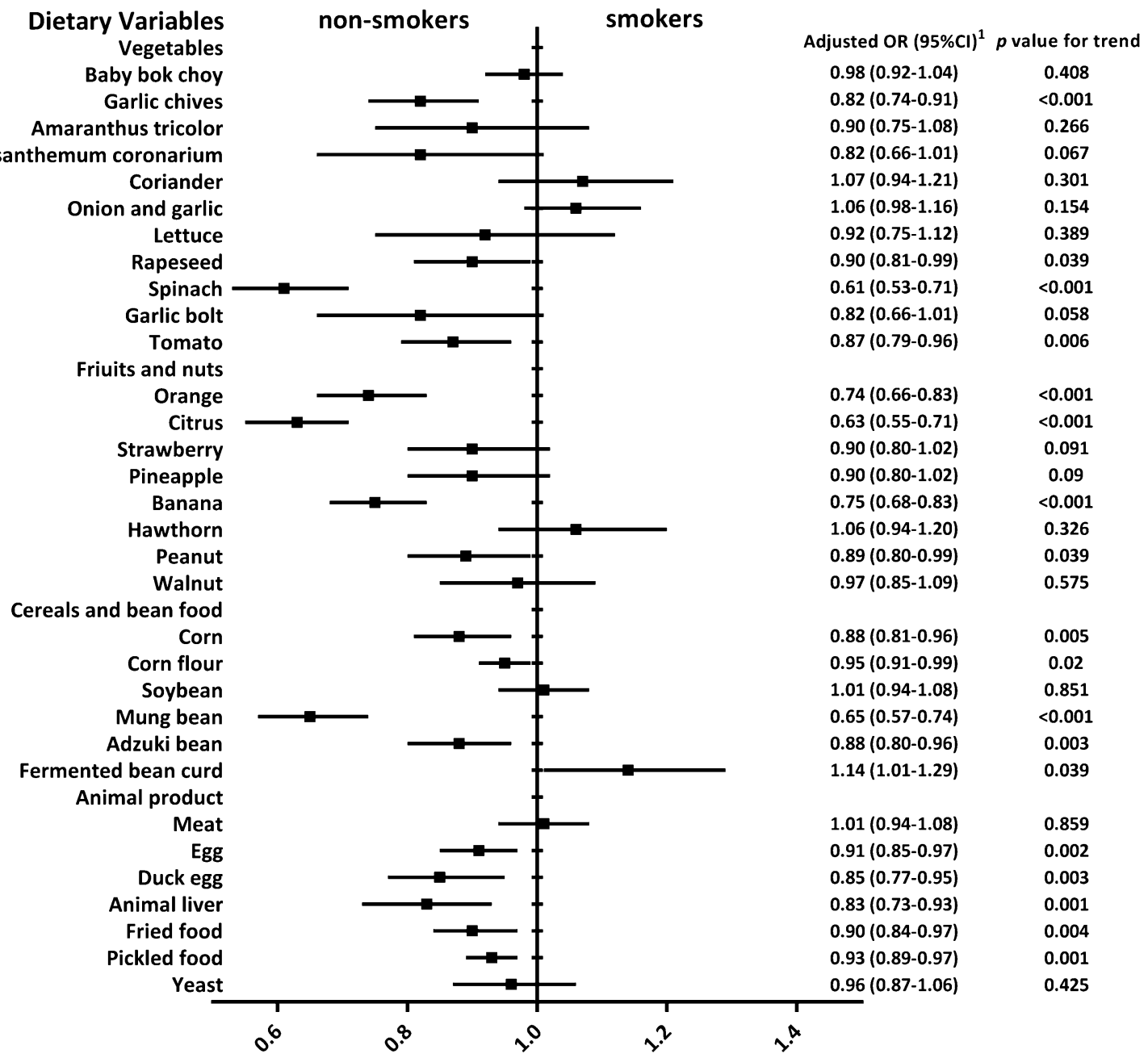

'Adjusted for gender, age, BMI, education level, annual income and alcohol units consumed per day.

Figure 4. Differences in dietary intake frequency between current smokers and non-smokers. The figure was created using GraphPad Prism 7.04 (https://www.graphpad.com/).

seem paradoxical in consideration of the metabolic effects of smoking, it has been assumed that heavy smokers may be more likely to have some other unhealthy lifestyles and habits such as heavy alcohol use ${ }^{4}$.

In order to verify the above hypothesis, the associations between alcohol use status and risk of being overweight or obese, and between smoking behavior and alcohol drinking were also assessed. Adjusted results in Table 3 illustrate strong positive associations between alcohol drinking behavior parameters and risk of being overweight or obese, with the statistically significant increasing trends found in alcohol units consumed per day, duration of drinking, earlier age at starting drinking, as well as cumulative amount of drinking. Thus, alcohol use is likely to be a risk factor of overweight and obesity in this middle-aged and elderly Chinese rural population with a significant dose-response relationship. An updated research summarized cross-sectional, longitudinal and experimental studies examining the link between alcohol consumption and obesity also concluded that it is reasonable to say that use of alcohol may be a risk factor for obesity in some populations, likely based on a multitude of factors ${ }^{40}$. Furthermore, Table 4 shows that heavy smokers were much more likely to be drinkers. Compared with non-smokers, heavy smokers smoked more than 20 cigarettes, experienced more than 35 years of smoking history, started smoking before 25 years old and had more than 30 pack-years of cumulative amount smoking were significantly associated with $4.88,4.89,4.96$ and 5.17 times increased risk of becoming a drinker, respectively. Figure 5 shows that a suppression effect of alcohol consumption would be present because the direct and mediated effects of smoking behavior on BMI had opposite signs, suggesting that the U-shaped relationship between smoking behaviors and BMI may be mediated by alcohol consumption to some extent. By integrating the results, it is logical to draw that heavy smokers and smokers starting smoking early may be more likely to have the habit of alcohol drinking than light smokers, and past a certain point, the increase in consumption of alcohol and its related high-fat diet, which is highly calorific, offsets the appetite suppression effects of smoking, and this is what leads to the high BMI and obesity levels in heavy smokers, and explains the U-shaped relationship between smoking behaviors and BMI. In addition, heavy drinking is usually accompanied by unhealthy dietary 


\begin{tabular}{|c|c|c|c|c|c|c|}
\hline Drinking behavior parameters & Overweight or obese, $\mathrm{n}=5182(\%)$ & $\begin{array}{l}\text { Underweight or normal, } \mathrm{n}=5655 \\
(\%)\end{array}$ & Crude OR (95\% CI) & $p$ value & Adjusted OR $(95 \% \mathrm{CI})^{\mathrm{a}}$ & $p$ value \\
\hline \multicolumn{7}{|c|}{ Alcohol units consumed per day } \\
\hline Non-drinker & $4109(79.3 \%)$ & $4801(84.9 \%)$ & 1.00 (referent) & - & 1.00 (referent) & - \\
\hline$<4$ & $207(4.0 \%)$ & $170(3.0 \%)$ & $1.42(1.16-1.75)$ & 0.001 & $1.56(1.25-1.93)$ & $<0.001$ \\
\hline $4-$ & $545(10.5 \%)$ & $438(7.7 \%)$ & $1.45(1.27-1.66)$ & $<0.001$ & $1.69(1.46-1.96)$ & $<0.001$ \\
\hline $8-$ & $321(6.2 \%)$ & $246(4.4 \%)$ & $1.53(1.29-1.81)$ & $<0.001$ & $1.76(1.45-2.13)$ & $<0.001$ \\
\hline$p$ value for trend & & & $<0.001$ & & $<0.001$ & \\
\hline \multicolumn{7}{|l|}{ Duration of drinking (years) } \\
\hline Non-drinker & $4109(79.3 \%)$ & $4801(84.9 \%)$ & 1.00 (referent) & - & 1.00 (referent) & - \\
\hline$<20$ & $327(6.3 \%)$ & $311(5.5 \%)$ & $1.23(1.05-1.44)$ & 0.012 & $1.36(1.14-1.61)$ & $<0.001$ \\
\hline $20-$ & $536(10.3 \%)$ & $386(6.8 \%)$ & $1.62(1.41-1.86)$ & $<0.001$ & $1.86(1.60-2.17)$ & $<0.001$ \\
\hline $35-$ & $210(4.1 \%)$ & $157(2.8 \%)$ & $1.56(1.27-1.93)$ & $<0.001$ & $1.97(1.57-2.48)$ & $<0.001$ \\
\hline$p$ value for trend & & & $<0.001$ & & $<0.001$ & \\
\hline \multicolumn{7}{|l|}{ Age at starting drinking (years) } \\
\hline Non-drinker & $4109(79.3 \%)$ & $4801(84.9 \%)$ & 1.00 (referent) & - & 1.00 (referent) & - \\
\hline $25-$ & $766(14.8 \%)$ & $669(11.8 \%)$ & $1.34(1.20-1.50)$ & $<0.001$ & $1.54(1.36-1.75)$ & $<0.001$ \\
\hline $20-$ & $184(3.5 \%)$ & $127(2.3 \%)$ & $1.69(1.35-2.13)$ & $<0.001$ & $1.93(1.51-2.46)$ & $<0.001$ \\
\hline$<20$ & $123(2.4 \%)$ & $58(1.0 \%)$ & $2.48(1.81-3.40)$ & $<0.001$ & $2.81(2.02-3.90)$ & $<0.001$ \\
\hline$p$ value for trend & & & $<0.001$ & & 0.001 & \\
\hline \multicolumn{7}{|c|}{ Cumulative amount of drinking (unit-years) } \\
\hline Non-drinker & $4109(79.3 \%)$ & $4801(84.9 \%)$ & 1.00 (referent) & - & 1.00 (referent) & - \\
\hline$<40$ & $177(3.4 \%)$ & $155(2.7 \%)$ & $1.33(1.07-1.66)$ & 0.010 & $1.43(1.14-1.80)$ & 0.002 \\
\hline $40-$ & $163(3.1 \%)$ & $144(2.5 \%)$ & $1.32(1.05-1.66)$ & 0.016 & $1.52(1.19-1.93)$ & 0.001 \\
\hline $80-$ & $159(3.1 \%)$ & $133(2.4 \%)$ & $1.40(1.11-1.77)$ & 0.005 & $1.59(1.24-2.04)$ & $<0.001$ \\
\hline $120-$ & $574(11.1 \%)$ & $422(7.5 \%)$ & $1.59(1.39-1.81)$ & $<0.001$ & $1.89(1.62-2.20)$ & $<0.001$ \\
\hline$p$ value for trend & & & $<0.001$ & & $<0.001$ & \\
\hline Liquor & $1042(20.1 \%)$ & $820(14.5 \%)$ & $1.48(1.34-1.64)$ & $<0.001$ & $1.70(1.51-1.92)$ & $<0.001$ \\
\hline Beer & $162(3.1 \%)$ & $120(2.1 \%)$ & $1.49(1.17-1.89)$ & 0.001 & $1.48(1.15-1.89)$ & 0.002 \\
\hline Wine & $19(0.4 \%)$ & $14(0.2 \%)$ & $1.48(0.74-2.96)$ & 0.264 & $1.54(0.76-3.12)$ & 0.231 \\
\hline
\end{tabular}

Table 3. ORs (and 95\% CIs) of being overweight or obese according to alcohol-related variables. ${ }^{\text {a Adjusted for }}$ gender, age, education level, annual income, number of cigarettes per day and consumptions of total vegetables, fresh fruits and meats

behavior in China such as high intake of saturated fat and calories, because residents may consume alcoholic drinks frequently when having dinner or midnight snack together.

A strength of the study was that it sampled a relatively unstudied demographic, and additionally, that demographic was one where potential variables were relatively stable, which means the sample group has the additional advantage of being relatively similar, thereby mitigating the impact of variables such as socio-economic status and diet, and improving the accuracy of the result. Furthermore, this study not only analysed the association between smoking and BMI, but also considered the roles of dietary factors and alcohol consumption, which may partly explain the U-shaped relationship between smoking and BMI: up to a certain point, smoking is associated with a decreased BMI, but beyond this, heavy smoking is associated with increased BMI and obesity.

Our study was limited by the possible recall bias brought by the questionnaire. The questionnaire collected the data of food frequency, but the information of portion size and accurate energy intake was unable to be obtained. In addition, this study was focused on current smokers, which means former smokers were excluded and not analysed. Furthermore, although dietary factors and alcohol use were taken into consideration, and several potential confounders were adjusted in the multiple logistic regression analyses, smokers and non-smokers may still differ with respect to other factors such as physical exercise. Previous studies that eliminated genetic effects by studying discordant identical twins found that compared with leaner cotwins, heavier cotwins generally tended to be less physically active and spend less time in moderate to vigorous physical activity ${ }^{41}$. Therefore, the lack of data involving physical activity could be a limitation of this study. It should also be pointed out that cross-sectional study has limitations in establishing a causal association.

In summary, dietary factors and alcohol use were found to play important roles in the relationship between smoking behaviors and BMI in the middle-aged and elderly Chinese rural population. The lower BMI of light smokers may be due to the well-documented appetite suppressive impacts of smoking. This correlates with our data where we saw decreased consumption of most food types amongst smokers. Certain types of strongly flavored foods were consumed more by smokers than non-smokers, but that this may be due to the affect that smoking has on taste perception. In addition, heavy smokers were more likely to have alcoholic drinking behavior, which would be positively associated with the risk of becoming overweight or obese, and consequently, leading 


\begin{tabular}{|c|c|c|c|c|c|c|}
\hline $\begin{array}{l}\text { Smoking behavior } \\
\text { parameters }\end{array}$ & Drinker, $\mathrm{n}=1927(\%)$ & $\begin{array}{l}\text { Non-drinker, } \\
\mathrm{n}=8910(\%)\end{array}$ & Crude OR $(95 \% \mathrm{CI})$ & $p$ value & $\begin{array}{l}\text { Adjusted OR (95\% } \\
\text { CI) }\end{array}$ & $p$ value \\
\hline \multicolumn{7}{|c|}{ Number of cigarettes smoked per day } \\
\hline Non-smoker & $775(40.2 \%)$ & $7055(79.2 \%)$ & 1.00 (referent) & - & 1.00 (referent) & - \\
\hline$<10$ & $156(8.1 \%)$ & $445(5.0 \%)$ & $3.19(2.62-3.89)$ & $<0.001$ & $2.31(1.85-2.88)$ & $<0.001$ \\
\hline $10-$ & $299(15.5 \%)$ & $724(8.1 \%)$ & $3.76(3.22-4.39)$ & $<0.001$ & $2.04(1.72-2.43)$ & $<0.001$ \\
\hline $20-$ & $697(36.2 \%)$ & $686(7.7 \%)$ & $9.25(8.13-10.52)$ & $<0.001$ & $4.88(4.20-5.66)$ & $<0.001$ \\
\hline$p$ value for trend & & & $<0.001$ & & $<0.001$ & \\
\hline \multicolumn{7}{|c|}{ Duration of smoking (years) } \\
\hline Non-smoker & $775(40.2 \%)$ & $7055(79.2 \%)$ & 1.00 (referent) & - & 1.00 (referent) & - \\
\hline$<20$ & $222(11.5 \%)$ & $774(8.7 \%)$ & $2.61(2.21-3.08)$ & $<0.001$ & $1.47(1.22-1.77)$ & $<0.001$ \\
\hline $20-$ & $558(29.0 \%)$ & $701(7.9 \%)$ & $7.25(6.34-8.28)$ & $<0.001$ & $4.30(3.69-5.02)$ & $<0.001$ \\
\hline $35-$ & $372(19.3 \%)$ & $380(4.2 \%)$ & $8.91(7.59-10.47)$ & $<0.001$ & $4.89(4.04-5.92)$ & $<0.001$ \\
\hline$p$ value for trend & & & $<0.001$ & & $<0.001$ & \\
\hline \multicolumn{7}{|c|}{ Age at starting smoking (years) } \\
\hline Non-smoker & $775(40.2 \%)$ & $7055(79.2 \%)$ & 1.00 (referent) & - & 1.00 (referent) & - \\
\hline $25-$ & $713(37.0 \%)$ & $1481(16.6 \%)$ & $4.38(3.90-4.92)$ & $<0.001$ & $2.66(2.33-3.04)$ & $<0.001$ \\
\hline$<25$ & $439(22.8 \%)$ & $374(4.2 \%)$ & $10.69(9.14-12.50)$ & $<0.001$ & $4.96(4.16-5.92)$ & $<0.001$ \\
\hline$p$ value for trend & & & $<0.001$ & & $<0.001$ & \\
\hline \multicolumn{7}{|c|}{ Cumulative amount of smoking (pack-years) } \\
\hline Non-smoker & $775(40.2 \%)$ & $7055(79.2 \%)$ & 1.00 (referent) & - & 1.00 (referent) & - \\
\hline$<15$ & $308(16.0 \%)$ & $967(10.8 \%)$ & $2.90(2.50-3.36)$ & $<0.001$ & $1.74(1.48-2.06)$ & $<0.001$ \\
\hline $15-$ & $342(17.7 \%)$ & $435(4.9 \%)$ & $7.16(6.10-8.40)$ & $<0.001$ & $4.27(3.55-5.13)$ & $<0.001$ \\
\hline $30-$ & $502(26.1 \%)$ & $453(5.1 \%)$ & $10.09(8.71-11.69)$ & $<0.001$ & $5.17(4.36-6.14)$ & $<0.001$ \\
\hline$p$ value for trend & & & $<0.001$ & & $<0.001$ & \\
\hline
\end{tabular}

Table 4. ORs (and 95\% CIs) of becoming a drinker according to smoking-related variables. ${ }^{\text {a Adjusted for }}$ gender, age, BMI, education level, annual income and consumptions of total vegetables, fresh fruits and meats.

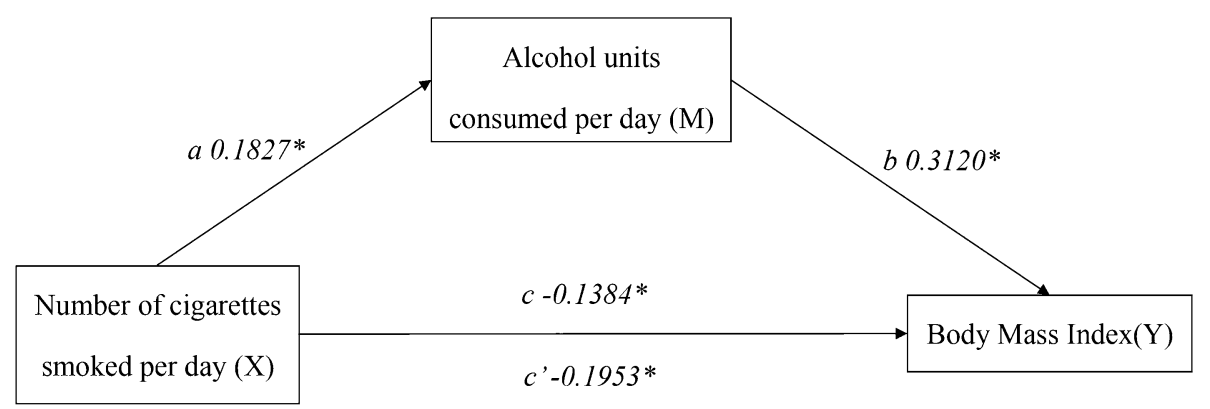

Figure 5. A schematic illustration of the model tested. The coefficient $a$ represents the effect of X (Number of cigarettes smoked per day) on the Mediator (M; Alcohol units consumed per day), the coefficient $b$ represents the effect of $\mathrm{M}$ on $\mathrm{Y}$ (Body Mass Index) controlling for $\mathrm{X}$, the coefficient $c$ ' represents the direct effect of $\mathrm{X}$ on $\mathrm{Y}$ while controlling for $\mathrm{M}$ and the coefficient $c$ represents the total effect of $\mathrm{X}$ on $\mathrm{Y}$. The indirect effect of $\mathrm{X}$ on $\mathrm{Y}$ was significant $(a b=0.0570 ; S E=0.0076 ; 95 \% \mathrm{CI}, 0.0423-0.0725) . c=c^{\prime}+a b$. Age, gender, education level, annual income and consumptions of total vegetables, fresh fruits and meats were controlled for by entering them into the models as covariates. ${ }^{*} \mathrm{p}<0.0001$.

to the U-shaped relationship between amount of smoking and risk of being overweight or obese. In addition, non-smokers and light smokers may be more likely to be within a normal BMI range than regular and heavy smokers, who were typically at more extreme ends of the spectrum.

This study has significant implications for government health campaigns. Smoking is seen by some as a good way of maintaining a low BMI, but our findings show that smoking is associated with other poor lifestyle choices (in this case high alcohol consumption and the negative change of diet) which can have other negative health effects, including unbalanced energy intake and unstable body weight, which may contribute to consequent health issues. Therefore, smoking may have an even more complex and negative role in human health than the already devastating effect seen to date. At present, there are far more alcohol- and tobacco-control activities than there were previously. Chinese government has been promoting the implementation of alcohol- and tobacco-control measures, but its role in the control of tobacco and alcohol use is in conflict with its reliance 
on the revenues of tobacco and alcohol by the selling of tobacco products and alcoholic drinks through the state-owned companies ${ }^{2,42,43}$. A hopeful sign is that China has ratified the World Health Organization (WHO) Framework Convention on Tobacco Control since 2005, and the Chinese tobacco epidemic has been addressed by the Chinese government although it is the owner of the largest cigarette monopoly worldwide ${ }^{43}$. Additionally, the government's latest healthcare plan, Healthy China 2030, has set a goal to reduce the adult smoking rate to $20 \%$ by $2030^{44}$. The WHO introduced six measures for tobacco control in 2008, called MPOWER: monitor tobacco use and prevention policies; protect people from tobacco use; offer help to quit tobacco use; warn about the dangers of tobacco; enforce bans on tobacco advertising, promotion, and sponsorship; and raise taxes on tobacco. Many countries have made significant progress in implementing these measures, but China still has a long way to $\mathrm{go}^{44}$. Furthermore, with the development of computer networks, online tobacco marketing has become a serious obstacle for tobacco control because of high volumes and wide coverage in China ${ }^{45}$. Therefore, for achieving the aim of Healthy China 2030, not only should the MPOWER measures be implemented, but network supervision also should be strengthened. We also need to realize clearly that the related public health issues will not be addressed in the short term without appropriate measures being adopted in the country.

\section{Methods}

Study population. Subjects included in the current study were selected from participants in the database of the Early Diagnosis and Early Treatment Project of Esophageal Cancer (EDETPEC) from January 2011 to December 2017, which was supported by the government and Cancer Foundation of China for benefiting rural residents ${ }^{46}$. In the present study, 10,837 middle-aged and elderly Chinese rural adults (6714 female and 4123 male) aged from 35 to 75 and free of cancers and precancerous lesions were included according to the results of routine endoscopy examination in EDETPEC. Individuals with a cancer history, cardiovascular and cerebrovascular diseases, Alzheimer's disease, schizophrenia, mobility problems, and other diseases that might influence their diet were also excluded. Of the 10,837 total sample size, 3007 people were current smokers and 7830 were non-smokers, whereas former smokers were not included. The study was approved by the Institutional Review Board of Southeast University Zhongda Hospital (no. 2012ZDllKY19.0) ${ }^{46-48}$, in accordance with the Declaration of Helsinki. All subjects signed written informed consent in the study, and the informed consent was obtained from legal guardian for the illiterate population.

Socio-demographic and anthropometric data. A questionnaire was used to collect socio-demographic data during the face-to-face interviews. Gender (male, female), age (35-50, 51-60, 61-75), education level (illiteracy, primary school, middle/high school, college/university) and family annual income per capita $(\leq 5000,5001-10,000,10,001-15,000, \geq 15,001 \mathrm{RMB})$ were obtained through the questionnaire at baseline and then classified into the categories listed in the above brackets.

Weight and height were measured using a conventional stadiometer and scale when subjects were in lightweight clothes without any shoes on. BMI was calculated as weight in kilograms divided by the square of the height in meters. Referring to the cutoff values for Chinese population recommended by the National Health and Family Planning Commission of the People's Republic of China ${ }^{49}$, BMI was categorized as underweight if $<18.5 \mathrm{~kg} / \mathrm{m}^{2}$, normal if between $18.5 \mathrm{~kg} / \mathrm{m}^{2}$ and $23.9 \mathrm{~kg} / \mathrm{m}^{2}$, overweight if between $24.0 \mathrm{~kg} / \mathrm{m}^{2}$ and $27.9 \mathrm{~kg} / \mathrm{m}^{2}$, and obese if $\geq 28.0 \mathrm{~kg} / \mathrm{m}^{2}$.

Assessment of tobacco and alcohol use. Smoking and drinking behavior parameters were obtained by questionnaire during the interview at recruitment. Subjects were asked what volume $(\mathrm{mL})$ of alcoholic beverages they consumed, on average, per day. Alcoholic beverages included beer, liquors, and wine. Alcohol units consumed per day ( 1 unit is $10 \mathrm{ml}$ of pure alcohol ${ }^{50}$ ) was calculated according to the common alcoholicity of the popular alcoholic beverages in China, assuming ethanol of $40 \mathrm{~mL}$ (4 units) for $100 \mathrm{~mL}$ liquor, $4 \mathrm{~mL}$ (0.4 unit) for $100 \mathrm{~mL}$ beer, and $10 \mathrm{~mL}$ (1 unit) for $100 \mathrm{~mL}$ wine. Additionally, other details of tobacco and alcohol use were also collected, including the average number of cigarettes smoked per day ( 1 pack has 20 cigarettes), duration of smoking/drinking habit (years) and age at which they started smoking/drinking. Cumulative consumption of tobacco/alcohol (pack-years/unit-years) was calculated as well.

Assessment of dietary intake. A validated qualitative food frequency questionnaire (FFQ) was performed to estimate dietary factors, covering 9 specific food categories (vegetables, fruits, nuts, cereals, bean food, animal product, fried food, pickled food and food made with yeast) and 29 specific food items that are commonly consumed in rural regions. Given that the seasonality would influence consumption frequency throughout the year, the FFQ accounted for the seasonality of some foods to ensure the accuracy of the calculation of frequency. Thus, subjects were asked how often they consumed the foods per week/per month/per year and how long, in months, they would consume this food yearly (e.g. 12 months for year round food, 2-3 months for very seasonal food). Then the data was standardized into 'times per week' averaged out over the course of a single year. Four frequency categories ranging from 'never', 'less than once a week', 'once a week or more but less than three times a week' to 'three or more times a week' were applied to the statistical analysis finally.

Statistical analysis. Continuous variables were expressed as the mean \pm standard deviation (SD) and adjusted in analysis of covariance. Student's t test was conducted to evaluate the significance of differences in body size parameters between smokers and non-smokers. Tamhane's T2 post-hoc test was performed to evaluate the significance of differences in smoking parameters among the four BMI categories in subjects after ranking variables within cases, as this test is appropriate in situations where the variance and/or sample size of groups is unequal. Unconditional univariate and multiple logistic regression analyses were conducted to compute crude 
and adjusted odds ratios (OR) and corresponding 95\% confidence intervals (CI), respectively. Confounders including gender, age, BMI, education level, family annual income per capita, number of cigarettes per day, alcohol units consumed per day and consumptions of total vegetables, fresh fruits and meats were adjusted when appropriate. The joint effects of age groups and three smoking behavior parameters on the risk of being overweight or obese by dividing the study subjects into 9 or 12 groups were further assessed. Interaction was examined using multiple logistic regression modeling. Based on continuous variables, the U-shaped relationship was further assessed using Two-lines test (version 0.52), which provides a valid alternative to the invalid testing of U-shaped relationships with quadratic regressions ${ }^{26}$. Meanwhile, tests for linear trends were carried out by assigning the median value of each category of smoking and drinking behavior parameters and BMI as a continuous variable in the models. Mediation analysis was performed using the SPSS PROCESS macro, version $3.4(\text { model } 4)^{51}$.

Questionnaire data was double-entered and validated using Epidata version 3.1 and then transformed into Microsoft Excel file. Analyses were carried out with the use of IBM SPSS Statistics version 22.0 (SPSS Inc., Chicago, IL, USA) and Two-lines test (version 0.52). Figures were created by GraphPad Prism 7.04 (GraphPad Software Inc., San Diego CA, USA) and Microsoft Excel 2007 (Microsoft Inc., Redmond, WA, USA). All reported p values were 2 -sided, and a p-value $<0.05$ was considered statistically significant.

\section{Data availability}

The technical appendix, statistical procedure, and dataset are available from the corresponding author.

Received: 19 June 2020; Accepted: 28 September 2020

Published online: 13 October 2020

\section{References}

1. Benedict, C. Golden-Silk Smoke: A History of Tobacco in China 1550-2010 (University of California Press, California, 2011).

2. Gu, D. F. et al. Mortality attributable to smoking in China. N. Engl. J. Med. 360, 150-159. https://doi.org/10.1056/Nejmsa0802902 (2009).

3. Khosla, T. \& Lowe, C. R. Obesity and smoking habits. Br. Med. J. 4, 10-13. https://doi.org/10.1136/bmj.4.5778.10 (1971).

4. Molarius, A., Seidell, J. C., Kuulasmaa, K., Dobson, A. J. \& Sans, S. Smoking and relative body weight: an international perspective from the WHO MONICA project. J. Epidemiol. Commun. Health 51, 252-260. https://doi.org/10.1136/jech.51.3.252 (1997).

5. Grunberg, N. E. Smoking cessation and weight-gain. N. Engl. J. Med. 324, 768-769. https://doi.org/10.1056/Nejm19910314324 $1111(1991)$.

6. Williamson, D. F. et al. Smoking cessation and severity of weight-gain in a national cohort. N. Engl. J. Med. 324, 739-745. https:// doi.org/10.1056/Nejm199103143241106 (1991).

7. Flegal, K. M., Troiano, R. P., Pamuk, E. R., Kuczmarski, R. J. \& Campbell, S. M. The influence of smoking cessation on the prevalence of overweight in the United-States. N. Engl. J. Med. 333, 1165-1170. https://doi.org/10.1056/Nejm199511023331801 (1995).

8. Saarni, S. E., Silventoinen, K., Rissanen, A., Sarlio-Lahteenkorva, S. \& Kaprio, J. Intentional weight loss and smoking in young adults. Int. J. Obes. Relat. Metab. Disord. 28, 796-802. https://doi.org/10.1038/sj.ijo.0802627 (2004).

9. Bean, M. K. et al. Rural adolescent attitudes toward smoking and weight loss: Relationship to smoking status. Nicotine Tob. Res. 10, 279-286. https://doi.org/10.1080/14622200701824968 (2008).

10. Audrain-McGovern, J. \& Benowitz, N. L. Cigarette smoking, nicotine, and body weight. Clin. Pharmacol. Ther. 90, 164-168. https ://doi.org/10.1038/clpt.2011.105(2011).

11. Fulkerson, J. A. \& French, S. A. Cigarette smoking for weight loss or control among adolescents: gender and racial/ethnic differences. J. Adolesc. Health 32, 306-313. https://doi.org/10.1016/S1054-139x(02)00566-9 (2003).

12. Camp, D. E., Klesges, R. C. \& Relyea, G. The relationship between body-weight concerns and adolescent smoking. Health Psychol. 12, 24-32. https://doi.org/10.1037/0278-6133.12.1.24 (1993).

13. Perkins, K. A., Sexton, J. E., Dimarco, A. \& Fonte, C. Acute effects of tobacco smoking on hunger and eating in male and female smokers. Appetite 22, 149-158. https://doi.org/10.1006/appe.1994.1014 (1994).

14. Perkins, K. A. Effects of tobacco smoking on caloric-intake. Br. J. Addict. 87, 193-205 (1992).

15. Dawson, D. A. Drinking as a risk factor for sustained smoking. Drug Alcohol. Depend. 59, 235-249. https://doi.org/10.1016/S0376 -8716(99)00130-1 (2000).

16. Wang, L., Lee, I. M., Manson, J. E., Buring, J. E. \& Sesso, H. D. Alcohol consumption, weight gain, and risk of becoming overweight in middle-aged and older women. Arch. Intern. Med. 170, 453-461. https://doi.org/10.1001/archinternmed.2009.527 (2010).

17. Suter, P. M. Is alcohol consumption a risk factor for weight gain and obesity?. Crit. Rev. Clin. Lab. Sci. 42, 197-227. https://doi. org/10.1080/10408360590913542 (2005).

18. Lahti-Koski, M., Pietinen, P., Heliovaara, M. \& Vartiainen, E. Associations of Body Mass Index and obesity with physical activity, food choices, alcohol intake, and smoking in the 1982-1997 FINRISK studies. Am. J. Clin. Nutr. 75, 809-817 (2002).

19. Fisher, M. \& Gordon, T. The relation of drinking and smoking-habits to diet-the lipid research clinics prevalence study. Am. J. Clin. Nutr. 41, 623-630 (1985).

20. Kromhout, D., Saris, W. H. \& Horst, C. H. Energy-intake, energy-expenditure, and smoking in relation to body fatness-the Zutphen study. Am. J. Clin. Nutr. 47, 668-674 (1988).

21. Wannamethee, S. G., Shaper, A. G. \& Whincup, P. H. Alcohol and adiposity: effects of quantity and type of drink and time relation with meals. Int. J. Obes. 29, 1436-1444. https://doi.org/10.1038/sj.ijo.0803034 (2005).

22. Rissanen, A. M., Heliovaara, M., Knekt, P., Reunanen, A. \& Aromaa, A. Determinants of weight-gain and overweight in adult finns. Eur. J. Clin. Nutr. 45, 419-430 (1991).

23. Ruf, T., Nagel, G., Altenburg, H. P., Miller, A. B. \& Thorand, B. Food and nutrient intake, anthropometric measurements and smoking according to alcohol consumption in the EPIC Heidelberg study. Ann. Nutr. Metab. 49, 16-25. https://doi.org/10.1159/00008 4173 (2005).

24. Sherwood, N. E., Jeffery, R. W., French, S. A., Hannan, P. J. \& Murray, D. M. Predictors of weight gain in the pound of prevention study. Int. J. Obes. 24, 395-403. https://doi.org/10.1038/sj.ijo.0801169 (2000).

25. Liu, S. M., Serdula, M. K., Williamson, D. F., Mokdad, A. H. \& Byers, T. A prospective-study of alcohol intake and change in bodyweight among us adults. Am. J. Epidemiol. 140, 912-920. https://doi.org/10.1093/oxfordjournals.aje.a117179 (1994).

26. Simonsohn, U. Two lines: a valid alternative to the invalid testing of U-shaped relationships with quadratic regressions. Adv. Methods Pract. Psychol. Sci. 1, 251524591880575. https://doi.org/10.1177/2515245918805755 (2018).

27. Wee, C. C., Rigotti, N. A., Davis, R. B. \& Phillips, R. S. Relationship between smoking and weight control efforts among adults in the United States. Arch. Intern. Med. 161, 546-550. https://doi.org/10.1001/archinte.161.4.546 (2001). 
28. Nematy, M. et al. The effect of hydroalcoholic extract of Coriandrum sativum on rat appetite. Avicenna J. Phytomed. 3, 91-97 (2013).

29. Myers, K. P. \& Pickering, C. Sensory variety during nursing increases young rats' acceptance of novel flavors after weaning. Appetite 49, 315. https://doi.org/10.1016/j.appet.2007.03.142 (2007).

30. Wu, P. et al. Phytochemical compositions of extract from peel of hawthorn fruit, and its antioxidant capacity, cell growth inhibition, and acetylcholinesterase inhibitory activity. BMC Complement. Altern. Med. 17, 151. https://doi.org/10.1186/s12906-017-1662-y (2017).

31. Campbell, S. C. Nutritional Recommendations for Athletes in Nutrition in the Prevention and Treatment of Disease 3rd edn (eds Coulston, A. M., Boushey, C. J. \& Ferruzzi, M. G.) 279-293 (Academic Press, Cambridge, 2013).

32. Gordon, T., Kannel, W. B., Dawber, T. R. \& McGee, D. Changes associated with quitting cigarette smoking: the Framingham study. Am. Heart J. 90, 322-328 (1975).

33. Noppa, H. \& Bengtsson, C. Obesity in relation to smoking: a population study of women in Goteborg Sweden. Prev. Med. 9, 534-543 (1980).

34. Jacobs, D. R. Jr. \& Gottenborg, S. Smoking and weight: the Minnesota Lipid Research Clinic. Am. J. Public Health 71, 391-396. https://doi.org/10.2105/ajph.71.4.391 (1981).

35. Albanes, D., Jones, D. Y., Micozzi, M. S. \& Mattson, M. E. Associations between smoking and body-weight in the united-states population-analysis of Nhanes-II. Am. J. Public Health 77, 439-444. https://doi.org/10.2105/Ajph.77.4.439 (1987).

36. Shimokata, H., Muller, D. C. \& Andres, R. Studies in the distribution of body fat. III. Effects of cigarette smoking. JAMA 261, 1169-1173 (1989).

37. Istvan, J. A., Cunningham, T. W. \& Garfinkel, L. Cigarette smoking and body weight in the Cancer Prevention Study I. Int. J. Epidemiol. 21, 849-853. https://doi.org/10.1093/ije/21.5.849 (1992).

38. Killen, J. D., Fortmann, S. P., Telch, M. J. \& Newman, B. Are heavy smokers different from light smokers-a comparison after 48 hours without cigarettes. JAMA 260, 1581-1585. https://doi.org/10.1001/jama.260.11.1581 (1988).

39. Istvan, J. A., Nides, M. A., Buist, A. S., Greene, P. \& Voelker, H. Salivary cotinine, frequency of cigarette-smoking, and body-mass index - findings at base-line in the lung health study. Am. J. Epidemiol. 139, 628-636. https://doi.org/10.1093/oxfordjournals.aje. a117052 (1994).

40. Traversy, G. \& Chaput, J. P. Alcohol consumption and obesity: an update. Curr. Obes. Rep. 4, 122-130. https://doi.org/10.1007/ s13679-014-0129-4 (2015).

41. Doornweerd, S. et al. Physical activity and dietary intake in BMI discordant identical twins. Obesity 24, 1349-1355. https://doi. org/10.1002/oby.21475 (2016).

42. Hu, T. W. et al. China at the crossroads: the economics of tobacco and health. Tob. Control 15, I37-I41. https://doi.org/10.1136/ tc.2005.014621 (2006).

43. Wright, A. A. \& Katz, I. T. Tobacco tightrope-balancing disease prevention and economic development in China. N. Engl. J. Med. 356, 1493-1496. https://doi.org/10.1056/NEJMp078018 (2007).

44. Guo, H. \& Quan, G. Tobacco control in China and the road to Healthy China 2030. Int. J. Tuberc. Lung Dis. 24, 271-277. https:// doi.org/10.5588/ijtld.19.0106 (2020).

45. Wang, X., Xiong, Y. \& Zhao, W. Tobacco control challenges in China: Big data analysis of online tobacco marketing information. Int. J. Nurs. Sci. https://doi.org/10.1016/j.ijnss.2020.07.002 (2020).

46. Pan, D. et al. A Distinct epidemiologic pattern of precancerous lesions of esophageal squamous cell carcinoma in a high-risk area of Huaian, Jiangsu Province, China. Cancer Prev. Res. 12, 449-462. https://doi.org/10.1158/1940-6207.capr-18-0462 (2019).

47. Pan, D. et al. MTHFR C677T genetic polymorphism in combination with serum vitamin B2, B12 and aberrant DNA methylation of P16 and P53 genes in esophageal squamous cell carcinoma and esophageal precancerous lesions: a case-control study. Cancer Cell Int. 19, 288. https://doi.org/10.1186/s12935-019-1012-x (2019).

48. Wang, S. et al. Corn flour intake, aflatoxin B1 exposure, and risk of esophageal precancerous lesions in a high-risk area of Huaian, China: a case-control study. Toxins 12, 299. https://doi.org/10.3390/toxins12050299 (2020).

49. National Health and Family Planning Commission of the People's Republic of China: Beijing, National Health, Family Planning Commission of the People's Republic of China. No. WS/T 428-2013: Criteria of Weight for Adults.https://www.nhc.gov.cn/ewebeditor/ uploadfile/2013/08/20130808135715967.pdf (2013).

50. Bellis, M. A. et al. The alcohol harm paradox: using a national survey to explore how alcohol may disproportionately impact health in deprived individuals. BMC Public Health 16, 111 (2016).

51. Hayes, A. Introduction to mediation, moderation, and conditional process analysis. J. Educ. Meas. 51, 335-337 (2013).

\section{Acknowledgements}

This study was funded by the National Natural Science Foundation of China (No. 81673147). The funding unit had no role in the whole study including study design, collection of data, analysis of results and composition of the manuscript. We thank all the participants, researchers and collaborators who were involved in the study for their efforts and contribution.

\section{Author contributions}

D.P., S.W. and G.S. designed research; D.P., S.W. M.S., J.W., K.W., P.L. and G.M. conducted research; S.W., M.S. and G.S. provided essential materials; D.P and J.S. analysed data; D.P. wrote paper; J.S. revised paper; S.W. obtained funding; G.S. had primary responsibility for final content. All authors read and approved the final manuscript.

\section{Competing interests}

The authors declare no competing interests.

\section{Additional information}

Supplementary information is available for this paper at https://doi.org/10.1038/s41598-020-74414-0.

Correspondence and requests for materials should be addressed to G.S.

Reprints and permissions information is available at www.nature.com/reprints.

Publisher's note Springer Nature remains neutral with regard to jurisdictional claims in published maps and institutional affiliations. 
(c) (i) Open Access This article is licensed under a Creative Commons Attribution 4.0 International cc) License, which permits use, sharing, adaptation, distribution and reproduction in any medium or format, as long as you give appropriate credit to the original author(s) and the source, provide a link to the Creative Commons licence, and indicate if changes were made. The images or other third party material in this article are included in the article's Creative Commons licence, unless indicated otherwise in a credit line to the material. If material is not included in the article's Creative Commons licence and your intended use is not permitted by statutory regulation or exceeds the permitted use, you will need to obtain permission directly from the copyright holder. To view a copy of this licence, visit http://creativecommons.org/licenses/by/4.0/.

(C) The Author(s) 2020 